\title{
In search of the best organ donation legislative system for Hong Kong: further research is needed
}

Hong Kong Med J 2018;24:318-9

DOI: $10.12809 / \mathrm{hkmj} 187371$

To the Editor-Transplantation is advancing rapidly to such an extent that in the foreseeable future we may witness the first head transplantation. ${ }^{1}$ Low donation rates will be one of the main global barriers undermining transplantation.

I read with interest the article by Cheung et $\mathrm{al}^{2}$ and I would like to highlight a few issues concerning this research. Although the article analysed the willingness of potential donors under three systems (opt-out, opt-in, and opt-in with allocation priority), it did not consider an opt-out system with allocation priority. Previous research showed that an opt-out system with allocation priority may result in a higher willingness to donate than other systems. ${ }^{3,4}$ Cheung et $\mathrm{al}^{2}$ found that the difference in willingness between the opt-in and opt-out systems was not significant; therefore, it is highly possible that an opt-out system with allocation priority would result in a similar, or perhaps better, willingness to an opt-in system with allocation priority. Moreover, the opinion of health care professionals on donation legislative systems is critical in this context, as they play a vital role in facilitating the process of donation and transplantation. ${ }^{5}$

Although the findings of Cheung et $\mathrm{al}^{2}$ are imperative, more accurate policy recommendations in this context require further studies to investigate willingness to donate under an opt-out system with allocation priority as well as health care professionals' opinion of donation legislative systems in Hong Kong.

\section{Declaration}

The author has no conflicts of interest to disclose. The author had full access to the data, contributed to the study, approved the final version for publication, and take responsibility for its accuracy and integrity.

Khaled Tafran *, MEc (Health Policy)

Department of Administrative Studies and Politics, Faculty of Economics and Administration, University of Malaya, Kuala Lumpur 50603, Malaysia

*Corresponding author: khaled@um.edu.my

\section{References}

1. Tafran K. Religious barriers to head transplantation: an Islamic viewpoint. Int J Surg 2017;43:92-3.

2. Cheung TK, Cheng TC, Wong LY. Willingness for deceased organ donation under different legislative systems in Hong
Kong: population-based cross-sectional survey. Hong Kong Med J 2018;24:119-27.

3. Tumin M, Tafran K, Mutalib MA, et al. Demographic and socioeconomic factors influencing public attitudes toward a presumed consent system for organ donation without and with a priority allocation scheme. Medicine (Baltimore) 2015;94:e1713.

4. Li D, Hawley Z, Schnier K. Increasing organ donation via changes in the default choice or allocation rule. J Health Econ 2013;32:1117-29.

5. Tumin M, Tafran K, Satar NM, et al. Factors associated with healthcare professionals' attitude towards the presumed consent system. Exp Clin Transplant. In press.

\section{Authors' reply}

To the Editor-We would like to thank Dr Tafran for his valuable comments on our article. ${ }^{1}$ First, in Spain, where the opt-out system is implemented, the deceased donor rate of 39.7 per million population (pmp) in 2015 (thanks for letting us know the typo of 34.0 reported in the Introduction $)^{2}$ increased to 46.9 pmp in 2017. On the contrary, in Hong Kong, where an opt-in system is adopted, the deceased donor rate has remained at around $6 \mathrm{pmp}$ over the same period of time. The gap between Hong Kong and Spain is large, and the gap is widening.

Second, as current participation in the opt-in system of deceased organ donation is low, our initial plan was to estimate the willingness rate under three proposed legislative options that have been adopted in other jurisdictions: "opt-out system", "opt-out system with allocation priority", and "opt-in system with allocation priority". Nonetheless our pilot study revealed that the majority of participants experienced difficulty in distinguishing between "the opt-out system with allocation priority" and the other two options as they were confused about the concepts inherent in these legislative options with similar definitions. Considering the length of the questionnaire and the limited interview time and feasibility, we decided to only examine the "optout system" and the "opt-in system with allocation priority" in the final study design. The media has subsequently reported these two proposed options and have since generated public debate regarding this issue. We suggest that the next survey can include more legislative options using examples from other jurisdictions as well as suggestions from interviewed participants. 
To summarise the key messages of our paper, TK Cheung, BSc

it is crucial to understand and explore various TC Cheng, BSC

stakeholders' perspective with respect to different legislative options for deceased organ donation. These stakeholders shall include health policymakers (eg, The Food and Health Bureau), and a variety of health care professionals and patient groups (eg, The Hong Kong Alliance of Patients' Organizations).

\section{Declaration}

The authors have no conflicts of interest to disclose. The authors had full access to the data, contributed to the study, approved the final version for publication, and take responsibility for its accuracy and integrity.

LY Wong *, MPH, PhD

The Jockey Club School of Public Health and Primary Care, The Chinese University of Hong Kong, Prince of Wales Hospital, Shatin, Hong Kong

*Corresponding author: lywong@cuhk.edu.hk

\section{References}

1. Cheung TK, Cheng TC, Wong LY. Willingness for deceased organ donation under different legislative systems in Hong Kong: population-based cross-sectional survey. Hong Kong Med J 2018;24:119-27.

2. International Registry in Organ Donation and Transplantation. 2018. Available from: http://www.irodat. org/. Accessed 23 Dec 2018. 